\title{
STRONG CONVERGENCE THEOREMS FOR STRICTLY ASYMPTOTICALLY PSEUDOCONTRACTIVE MAPPINGS IN HILBERT SPACES
}

\author{
Gurucharan Singh Saluja ${ }^{1}$ and Hemant Kumar Nashine ${ }^{2}$ \\ ${ }^{1}$ Department of Mathematics \& Information Technology, Govt. Nagarjuna \\ P.G. College of Science,Raipur(Chhattisgarh), \\ India_saluja_1963@rediffmail.com \\ ${ }^{2}$ Department of Mathematics, Disha Institute of Management and \\ Technology, Satya Vihar, Vidhansabha-Chandrakhuri Marg, Mandir Hasaud, \\ Raipur-492101(Chhattisgarh), India_hnashine@rediffmail.com, \\ nashine_09@rediffmail.com
}

\begin{abstract}
We propose a new $(C Q)$ algorithm for strictly asymptotically pseudocontractive mappings and obtain a strong convergence theorem for this class of mappings in the framework of Hilbert spaces.

Key words and Phrases: $C Q$-iteration, strictly asymptotically pseudo-contractive mapping, common fixed point, implicit iteration, strong convergence, Hilbert space.

Abstrak. Penulis mengajukan suatu algoritma baru (CQ) untuk pemetaan pseudocontractive yang asimtotik kuat dan memperoleh sebuah teorema konvergesi kuat untuk kelas pemetaan ini pada kerangka kerja ruang Hilbert.
\end{abstract}

Key words and Phrases: Iterasi $C Q$, pemetaan pseudo-contractive yang asimtotik kuat, titik tetap umum, iterasi implicit, konvergensi kuat, ruang Hilbert

\section{Introduction and Preliminaries}

Throughout this paper, let $H$ be a real Hilbert space with the scalar product and norm denoted by the symbols $\langle.,$.$\rangle and \|$.$\| respectively. Let C$ be a closed convex subset of $H$, we denote by $P_{C}($.$) the metric projection from H$ onto $C$. It is known that $z=P_{C}(x)$ is equivalent to $\langle z-y, x-z\rangle \geq 0$ for every $y \in C$. A point $x \in C$ is a fixed point of $T$ provided that $T x=x$. Denote by $F(T)$ the set of fixed point of $T$, that is, $F(T)=\{x \in C: T x=x\}$. It is known that $F(T)$ is closed and convex. Let $T$ be a (possibly) nonlinear mapping from $C$ into $C$. We now consider the following classes:

2000 Mathematics Subject Classification: 47H09, 47H10.

Received: 20-02-2010, accepted: 30-07-2010. 
(I) $T$ is contractive, i.e., there exists a constant $k<1$ such that

$$
\|T x-T y\| \leq k\|x-y\|,
$$

for all $x, y \in C$.

(II) $T$ is nonexpansive, i.e.,

$$
\|T x-T y\| \leq\|x-y\|,
$$

for all $x, y \in C$.

(III) $T$ is uniformly $L$-Lipschitzian, i.e., if there exists a constant $L>0$ such that

$$
\left\|T^{n} x-T^{n} y\right\| \leq L\|x-y\|,
$$

for all $x, y \in C$ and $n \in \mathbb{N}$.

(IV) $T$ is pseudo-contractive, i.e.,

$$
\langle T x-T y, j(x-y)\rangle \leq\|x-y\|^{2},
$$

for all $x, y \in C$.

(V) $T$ is strictly pseudo-contractive, i.e., there exists a constant $k \in[0,1)$ such that

$$
\|T x-T y\|^{2} \leq\|x-y\|^{2}+k\|(x-T x)-(y-T y)\|^{2},
$$

for all $x, y \in C$.

(VI) $T$ is asymptotically nonexpansive [4], i.e., if there exists a sequence $\left\{r_{n}\right\} \subset$ $[0, \infty)$ with $\lim _{n \rightarrow \infty} r_{n}=0$ such that

$$
\left\|T^{n} x-T^{n} y\right\| \leq\left(1+r_{n}\right)\|x-y\|,
$$

for all $x, y \in C$ and $n \in \mathbb{N}$.

(VII) $T$ is $k$-strictly asymptotically pseudo-contractive [14], i.e., if there exists a sequence $\left\{r_{n}\right\} \subset[0, \infty)$ with $\lim _{n \rightarrow \infty} r_{n}=0$ such that

$$
\begin{aligned}
\left\|T^{n} x-T^{n} y\right\|^{2} \leq & \left(1+r_{n}\right)^{2}\|x-y\|^{2} \\
& +k\left\|\left(x-T^{n} x\right)-\left(y-T^{n} y\right)\right\|^{2}
\end{aligned}
$$

for some $k \in[0,1)$ for all $x, y \in C$ and $n \in \mathbb{N}$.

Remark 1.1. [14] . If $T$ is $k$-strictly asymptotically pseudo-contractive mapping, then it is uniformly L-Lipschitzian, but the converse does not hold. It can be shown as:

Observe that if $T$ is $k$-strictly asymptotically pseudo-contractive, taking $1+$ $r_{n}=a_{n}$ in (7) with $\lim _{n \rightarrow \infty} a_{n}=1$ since $\lim _{n \rightarrow \infty} r_{n}=0$, then for all $x, y \in C$, we have from (7) that

$$
\begin{aligned}
\left\|T^{n} x-T^{n} y\right\|^{2} & \leq a_{n}^{2}\|x-y\|^{2}+k\left\|\left(x-T^{n} x\right)-\left(y-T^{n} y\right)\right\|^{2} \\
& =\left(a_{n}\|x-y\|\right)^{2}+\left(\sqrt{k}\left\|\left(x-T^{n} x\right)-\left(y-T^{n} y\right)\right\|\right)^{2} \\
& \leq\left(a_{n}\|x-y\|+\sqrt{k}\left\|\left(x-T^{n} x\right)-\left(y-T^{n} y\right)\right\|\right)^{2} .
\end{aligned}
$$


Thus

$$
\begin{aligned}
\left\|T^{n} x-T^{n} y\right\| & \leq a_{n}\|x-y\|+\sqrt{k}\left\|\left(x-T^{n} x\right)-\left(y-T^{n} y\right)\right\| \\
& \leq a_{n}\|x-y\|+\sqrt{k}\|x-y\|-\sqrt{k}\left\|T^{n} x-T^{n} y\right\|,
\end{aligned}
$$

so that

$$
\left\|T^{n} x-T^{n} y\right\| \leq \frac{a_{n}+\sqrt{k}}{1-\sqrt{k}}\|x-y\| .
$$

Since $\left\{a_{n}\right\}$ is bounded, then $a_{n} \leq a$ for all $n \geq 0$ and for some $a>0$. Hence

$$
\left\|T^{n} x-T^{n} y\right\| \leq \frac{a_{n}+\sqrt{k}}{1-\sqrt{k}}\|x-y\|=L\|x-y\|,
$$

where $L=\frac{a+\sqrt{k}}{1-\sqrt{k}}$. This implies that a $k$-strictly asymptotically pseudo-contractive mapping is uniformly $L$-Lipschitzian.

The class of strictly pseudo-contractive mappings have been studied by several authors (see, for example $[2,5,11,16]$ and references therein.).

In case of contractive mapping, the Banach Contraction Principle guarantee not only the existence of unique fixed point, but also to obtain the fixed point by successive approximation (or Picard iteration). But for outside the class of contractive mapping, the classical iteration scheme no longer applies. So some other iteration scheme is required.

Two iteration processes are often used to approximate fixed point of nonexpansive and pseudo-contractive mappings. The first iteration process is known as Mann's iteration [12], where $\left\{x_{n}\right\}$ is defined as

$$
x_{n+1}=\alpha_{n} x_{n}+\left(1-\alpha_{n}\right) T x_{n}, \quad n \geq 0
$$

where the initial guess $x_{0}$ is taken in $C$ arbitrary and the sequence $\left\{\alpha_{n}\right\}$ is in the interval $[0,1]$.

The second iteration process is known as Ishikawa iteration process [6] which is defined by

$$
\begin{aligned}
x_{n+1} & =\alpha_{n} x_{n}+\left(1-\alpha_{n}\right) T y_{n}, \\
y_{n} & =\beta_{n} x_{n}+\left(1-\beta_{n}\right) T x_{n} ; \quad n \geq 0
\end{aligned}
$$

where the initial guess $x_{0}$ is taken in $C$ arbitrary and $\left\{\alpha_{n}\right\}$ and $\left\{\beta_{n}\right\}$ are sequences in the interval $[0,1]$.

Process (9) is indeed more general than the process (8). But research has been concentrated on the later, probably due to the reason that process $(8)$ is simpler and that a convergence theorem for process (8) may possibly lead to a convergence theorem for process $(9)$, provided that the sequence $\left\{\beta_{n}\right\}$ satisfy certain appropriate conditions.

If $T$ is a nonexpansive mapping with a fixed point and the control sequence $\left\{\alpha_{n}\right\}$ is chosen so that $\sum_{n=0}^{\infty} \alpha_{n}\left(1-\alpha_{n}\right)=\infty$, then the sequence $\left\{x_{n}\right\}$ generated by Mann's iteration process (8) converges weakly to a fixed point of $T$ (this is 
also valid in a uniformly convex Banach space with the Fréchet differentiable norm [18]). However we note that Mann's iterations have only weak convergence even in Hilbert space [3].

Attempts to modify the Mann iteration method (8) so that strong convergence is guaranteed have recently been made. Nakajo and Takahashi [13] proposed the following modification of Mann iteration method (8) for a single nonexpansive mapping $T$ in a Hilbert space $H$ :

$$
x_{0} \in C \text { chosen arbitrary }
$$

$$
\begin{aligned}
y_{n} & =\alpha_{n} x_{n}+\left(1-\alpha_{n}\right) T x_{n}, \\
C_{n} & =\left\{z \in C:\left\|y_{n}-z\right\| \leq\left\|x_{n}-z\right\|\right\}, \\
Q_{n} & =\left\{z \in C:\left\langle x_{n}-z, x_{0}-x_{n}\right\rangle \geq 0\right\}, \\
x_{n+1} & =P_{C_{n} \cap Q_{n}}\left(x_{0}\right) .
\end{aligned}
$$

They proved that if the sequence $\left\{\alpha_{n}\right\}$ is bounded above from one, then the sequence $\left\{x_{n}\right\}$ generated by (10) converges strongly to $P_{F(T)}\left(x_{0}\right)$.

Algorithm (10) is called a $(C Q)$ algorithm for the Mann iteration method because at each step the Mann iterate (denoted by $y_{n}$ in (10)) is used to construct the sets $C_{n}$ and $Q_{n}$ which are in turn used to construct the next iterate $x_{n+1}$.

In algorithm (10) the initial guess $x_{0}$ is projected onto the intersection of two suitably constructed closed convex subsets $C_{n}$ and $Q_{n}$.

In 2006, Kim and Xu [7] adapted the iteration (10) to asymptotically nonexpansive mappings. They introduced the following iteration process for asymptotically nonexpansive mappings in Hilbert space $H$ :

$$
\begin{aligned}
& x_{0} \in C \text { chosen arbitrary, } \\
y_{n}= & \alpha_{n} x_{n}+\left(1-\alpha_{n}\right) T x_{n}, \\
C_{n}= & \left\{z \in C:\left\|y_{n}-z\right\|^{2} \leq\left\|x_{n}-z\right\|^{2}+\theta_{n}\right\}, \\
Q_{n}= & \left\{z \in C:\left\langle x_{n}-z, x_{0}-x_{n}\right\rangle \geq 0\right\}, \\
x_{n+1}= & P_{C_{n} \cap Q_{n}}\left(x_{0}\right),
\end{aligned}
$$

where

$$
\theta_{n}=\left(1-\alpha_{n}\right)\left(\left(1+r_{n}\right)^{2}-1\right)(\operatorname{diam} C)^{2} \rightarrow 0 \text { as } n \rightarrow \infty .
$$

Recently, Marino and $\mathrm{Xu}$ [11] extended $(C Q)$ algorithm from nonexpansive mappings to strict pseudo-contractive mappings.

It is important note that the set $C_{n}$ in the $(C Q)$ algorithm differs among distinct classes of mappings.

In recent years, the implicit iteration scheme for approximating fixed points of nonlinear mappings has been introduced and studied by several authors.

In 2001, Xu and Ori [20] have introduced the following implicit iteration process for common fixed points of a finite family of nonexpansive mappings $\left\{T_{i}\right\}_{i=1}^{N}$ 
in Hilbert spaces:

$$
x_{n}=t_{n} x_{n-1}+\left(1-t_{n}\right) T_{n} x_{n}, \quad n \geq 1
$$

where $T_{n}=T_{n \bmod N}$. (Here the $\bmod \mathrm{N}$ function takes values in $\left.\{1,2, \ldots, N\}\right)$. And they proved the weak convergence of the process (12).

Very recently, Acedo and $\mathrm{Xu}$ [1] still in the framework of Hilbert spaces introduced the following cyclic algorithm.

Let $C$ be a closed convex subset of a Hilbert space $H$ and let $\left\{T_{i}\right\}_{i=0}^{N-1}$ be $N k$-strict pseudo-contractions on $C$ such that $F=\bigcap_{i=0}^{N-1} F\left(T_{i}\right) \neq \emptyset$. Let $x_{0} \in C$ and let $\left\{\alpha_{n}\right\}$ be a sequence in $(0,1)$. The cyclic algorithm generates a sequence $\left\{x_{n}\right\}_{n=1}^{\infty}$ in the following way:

$$
\begin{aligned}
x_{1} & =\alpha_{0} x_{0}+\left(1-\alpha_{0}\right) T_{0} x_{0}, \\
x_{2} & =\alpha_{1} x_{1}+\left(1-\alpha_{1}\right) T_{1} x_{1}, \\
& \vdots \\
x_{N} & =\alpha_{N-1} x_{N-1}+\left(1-\alpha_{N-1}\right) T_{N-1} x_{N-1}, \\
x_{N+1} & =\alpha_{N} x_{N}+\left(1-\alpha_{N}\right) T_{0} x_{N}, \\
& \vdots
\end{aligned}
$$

In general, $\left\{x_{n+1}\right\}$ is defined by

$$
x_{n+1}=\alpha_{n} x_{n}+\left(1-\alpha_{n}\right) T_{[n]} x_{n},
$$

where $T_{[n]}=T_{i}$ with $i=n(\bmod N), 0 \leq i \leq N-1$. They also proved a weak convergence theorem for $k$-strict pseudo-contractions in Hilbert spaces by cyclic algorithm (13).

We note that it is the same as Mann's iterations that have only weak convergence theorems with implicit iteration scheme (12) and (13). In this paper, we introduce the following implicit iteration scheme and modify it by hybrid method, so strong convergence theorems are obtained:

Let $C$ be a closed convex subset of a Hilbert space $H$ and let $\left\{T_{i}\right\}_{i=0}^{N-1}$ be $N k$ strictly asymptotically pseudo-contractions on $C$ such that $F=\bigcap_{i=0}^{N-1} F\left(T_{i}\right) \neq \emptyset$. Let $x_{0} \in C$ and let $\left\{\alpha_{n}\right\}$ be a sequence in $(0,1)$. The implicit iteration scheme generates a sequence $\left\{x_{n}\right\}_{n=0}^{\infty}$ in the following way:

$$
x_{n+1}=\alpha_{n} x_{n}+\left(1-\alpha_{n}\right) T_{[n]}^{s} x_{n},
$$

where $T_{[n]}^{s}=T_{n(\bmod N)}^{s}=T_{i}^{s}$ with $n=s N+i$ and $i \in I=\{0,1, \ldots, N-1\}$.

Observe that if $C$ is a nonempty closed convex subset of a real Hilbert space $H$ and $\left\{T_{i}\right\}_{i=0}^{N-1}: C \rightarrow C$ be $N k$-strictly asymptotically pseudo-contractive mappings. If $\left(1-\alpha_{n}\right) L<1$, where $L=\max \left\{L_{i}: i=0,1, \ldots, N-1\right\}$, then for given $x_{n} \in C$, the mapping $W_{n}: C \rightarrow C$ defined by

$$
W_{n}(x)=\alpha_{n} x_{n}+\left(1-\alpha_{n}\right) T_{[n]}^{s} x, \forall n \geq 1,
$$


is a contraction mapping. In fact, the following are observed

$$
\begin{aligned}
\left\|W_{n} x-W_{n} y\right\| & =\left\|\alpha_{n} x_{n}+\left(1-\alpha_{n}\right) T_{[n]}^{s} x-\left(\alpha_{n} x_{n}+\left(1-\alpha_{n}\right) T_{[n]}^{s} y\right)\right\| \\
& =\left(1-\alpha_{n}\right)\left\|T_{[n]}^{s} x-T_{[n]}^{s} y\right\| \\
& \leq\left(1-\alpha_{n}\right) L\|x-y\|, \forall x, y \in C .
\end{aligned}
$$

Since $\left(1-\alpha_{n}\right) L<1$ for all $n \geq 1$, hence $W_{n}: C \rightarrow C$ is a contraction mapping. By Banach contraction mapping principle, there exists a unique fixed point $x_{n} \in C$ such that

$$
x_{n}=\alpha_{n} x_{n}+\left(1-\alpha_{n}\right) T_{[n]}^{s} x, \forall n \geq 1 .
$$

Therefore, if $\left(1-\alpha_{n}\right) L<1$ for all $n \geq 1$, then the iterative sequence (14) can be employed for the approximation of common fixed points for a finite family of $k$-strictly asymptotically pseudo-contractive mappings.

It is the purpose of this paper to modify iteration process (14) by hybrid method as follows:

$$
x_{0} \in C \text { chosen arbitrary, }
$$

$$
\begin{aligned}
y_{n}= & \alpha_{n} x_{n}+\left(1-\alpha_{n}\right) T_{[n]}^{s} x_{n}, \\
C_{n}= & \left\{z \in C:\left\|y_{n}-z\right\|^{2} \leq\left\|x_{n}-z\right\|^{2}\right. \\
& \left.\quad+\left(k-\alpha_{n}\right)\left\|x_{n}-T_{[n]}^{s} x_{n}\right\|^{2}+\lambda_{n}\right\}, \\
Q_{n}= & \left\{z \in C:\left\langle x_{n}-z, x_{0}-x_{n}\right\rangle \geq 0\right\}, \\
x_{n+1}= & P_{C_{n} \cap Q_{n}}\left(x_{0}\right),
\end{aligned}
$$

where $T_{[n]}^{s}=T_{n(\bmod N)}^{s}=T_{i}^{s}$ with $n=s N+i$ and $i \in I=\{0,1, \ldots, N-1\}$ and

$$
\lambda_{n}=\left(1-\alpha_{n}\right)\left(\left(1+r_{n}\right)^{2}-1\right)(\operatorname{diam} C)^{2} \rightarrow 0 \text { as } n \rightarrow \infty .
$$

The purpose of this paper is to establish strong convergence theorems of newly proposed $(C Q)$ algorithm (18) for finite family of $k$-strictly asymptotically pseudo-contractive mappings in Hilbert spaces. Our results extend the corresponding results of Liu [9], Kim and Xu [8], Osilike and Akuchu [15], Thakur [19] and some others.

In the sequel, we will need the following lemmas.

Lemma 1.2. Let $H$ be a real Hilbert space. There holds the following identities:

(i) $\|x-y\|^{2}=\|x\|^{2}-\|y\|^{2}-2\langle x-y, y\rangle \quad \forall x, y \in H$.

(ii) $\|t x+(1-t) y\|^{2}=t\|x\|^{2}+(1-t)\|y\|^{2}-t(1-t)\|x-y\|^{2}$,

$\forall t \in[0,1], \forall x, y \in H$.

(iii) If $\left\{x_{n}\right\}$ be a sequence in $H$ weakly converges to $z$, then

$$
\limsup _{n \rightarrow \infty}\left\|x_{n}-y\right\|^{2}=\limsup _{n \rightarrow \infty}\left\|x_{n}-z\right\|^{2}+\|z-y\|^{2} \quad \forall y \in H .
$$


Lemma 1.3. Let $H$ be a real Hilbert space. Given a closed convex subset $C \subset H$ and points $x, y, z \in H$. Given also a real number $a \in \mathbb{R}$. The set

$$
\left\{v \in C:\|y-v\|^{2} \leq\|x-v\|^{2}+\langle z, v\rangle+a\right\}
$$

is convex (and closed).

Lemma 1.4. Let $K$ be a closed convex subset of a real Hilbert space $H$. Given $x \in H$ and $y \in K$. Then $z=P_{K} x$ if and only if there holds the relation

$$
\langle x-z, y-z\rangle \leq 0 \quad \forall y \in K,
$$

where $P_{K}$ is the nearest point projection from $H$ onto $K$, that is, $P_{K} x$ is the unique point in $K$ with the property

$$
\left\|x-P_{K} x\right\| \leq\|x-y\| \quad \forall x \in K .
$$

We use following notation:

1. $\rightarrow$ for weak convergence and $\rightarrow$ for strong convergence.

2. $\omega_{w}\left(x_{n}\right)=\left\{x: \exists x_{n_{j}} \rightarrow x\right\}$ denotes the weak $\omega$-limit set of $\left\{x_{n}\right\}$.

Lemma 1.5. [10]. Let $K$ be a closed convex subset of $H$. Let $\left\{x_{n}\right\}$ be a sequence in $H$ and $u \in H$. Let $q=P_{K} u$. If $\left\{x_{n}\right\}$ is such that $\omega_{w}\left(x_{n}\right) \subset K$ and satisfies the condition

$$
\left\|x_{n}-u\right\|=\|u-q\| \forall n .
$$

Then $x_{n} \rightarrow q$.

Lemma 1.6. [17]. Let $\left\{a_{n}\right\}_{n=1}^{\infty},\left\{\beta_{n}\right\}_{n=1}^{\infty}$ and $\left\{r_{n}\right\}_{n=1}^{\infty}$ be sequences of nonnegative real numbers satisfying the inequality

$$
a_{n+1} \leq\left(1+r_{n}\right) a_{n}+\beta_{n}, \quad n \geq 1 .
$$

If $\sum_{n=1}^{\infty} r_{n}<\infty$ and $\sum_{n=1}^{\infty} \beta_{n}<\infty$, then $\lim _{n \rightarrow \infty} a_{n}$ exists. If in addition $\left\{a_{n}\right\}_{n=1}^{\infty}$ has a subsequence which converges strongly to zero, then $\lim _{n \rightarrow \infty} a_{n}=0$.

Lemma 1.7. Let $H$ be a real Hilbert space, let $C$ be a nonempty closed convex subset of $H$, and let $T_{i}: C \rightarrow C$ be a $k_{i}$-strictly asymptotically pseudocontractive mapping for $i=0,1, \ldots, N-1$ with a sequence $\left\{r_{n_{i}}\right\} \subset[0, \infty)$ such that $\sum_{n=1}^{\infty} r_{n_{i}}<\infty$ and for some $0 \leq k_{i}<1$, then there exist constants $L>0$ and $k \in[0,1)$ and $a$ sequence $\left\{r_{n}\right\} \subset[0, \infty)$ with $\lim _{n \rightarrow \infty} r_{n}=0$ such that for any $x, y \in C$ and for each $i=0,1, \ldots, N-1$ and each $n \geq 1$, the following hold:

$$
\begin{aligned}
\left\|T_{i}^{n} x-T_{i}^{n} y\right\| \leq & \left(1+r_{n}\right)^{2}\|x-y\|^{2} \\
& +k\left\|\left(x-T_{i}^{n} x\right)-\left(y-T_{i}^{n} y\right)\right\|^{2},
\end{aligned}
$$

and

$$
\left\|T_{i}^{n} x-T_{i}^{n} y\right\| \leq L\|x-y\|
$$

Proof. Since for each $i=0,1, \ldots, N-1, T_{i}$ is $k_{i}$-strictly asymptotically pseudocontractive, where $k_{i} \in[0,1)$ and $\left\{r_{n_{i}}\right\} \subset[0, \infty)$ with $\lim _{n \rightarrow \infty} r_{n_{i}}=0$. By 
Remark 1.1, $T_{i}$ is $L_{i}$-Lipschitzian. Taking $r_{n}=\max \left\{r_{n_{i}}, i=0,1, \ldots, N-1\right\}$ and $k=\max \left\{k_{i}, i=0,1, \ldots, N-1\right\}$, hence, for each $i=0,1, \ldots, N-1$, we have

$$
\begin{aligned}
\left\|T_{i}^{n} x-T_{i}^{n} y\right\| \leq & \left(1+r_{n_{i}}\right)^{2}\|x-y\|^{2} \\
& +k_{i}\left\|\left(x-T_{i}^{n} x\right)-\left(y-T_{i}^{n} y\right)\right\|^{2}, \\
\leq & \left(1+r_{n}\right)^{2}\|x-y\|^{2} \\
& +k\left\|\left(x-T_{i}^{n} x\right)-\left(y-T_{i}^{n} y\right)\right\|^{2} .
\end{aligned}
$$

The conclusion (20) is proved. Again taking $L=\max \left\{L_{i}: i=0,1, \ldots, N-1\right\}$ for any $x, y \in C$, we have

$$
\left\|T_{i}^{n} x-T_{i}^{n} y\right\| \leq L_{i}\|x-y\| \leq L\|x-y\| .
$$

This completes the proof of lemma.

\section{Main Results}

Theorem 2.1. Let $C$ be a closed convex subset of a Hilbert space $H$. Let $N \geq 1$ be an integer. Let for each $0 \leq i \leq N-1, T_{i}: C \rightarrow C$ be $N k_{i}$-strictly asymptotically pseudo-contraction mappings for some $0 \leq k_{i}<1$ and $\sum_{n=1}^{\infty} r_{n}<\infty$. Let $k=$ $\max \left\{k_{i}: 0 \leq i \leq N-1\right\}$ and $r_{n}=\max \left\{r_{n_{i}}: 0 \leq i \leq N-1\right\}$. Assume that $F=\bigcap_{i=0}^{N-1} F\left(T_{i}\right) \neq \emptyset$. Given $x_{0} \in C$, let $\left\{x_{n}\right\}_{n=0}^{\infty}$ be the sequence generated by an implicit iteration scheme (14). Assume that the control sequence $\left\{\alpha_{n}\right\}$ is chosen so that $k+\epsilon<\alpha_{n}<1-\epsilon$ for all $n$ and for some $\epsilon \in(0,1)$. Then $\lim _{n \rightarrow \infty}\left\|x_{n}-T_{[l]} x_{n}\right\|=0$ for all $l \in I=\{0,1, \ldots, N-1\}$.

Proof. Let $p \in F=\bigcap_{i=0}^{N-1} F\left(T_{i}\right)$. It follows from (14) and Lemma 1.2 (ii) that

$$
\begin{aligned}
\left\|x_{n+1}-p\right\|^{2}= & \left\|\alpha_{n} x_{n}+\left(1-\alpha_{n}\right) T_{[n]}^{s} x_{n}-p\right\|^{2} \\
= & \left\|\alpha_{n}\left(x_{n}-p\right)+\left(1-\alpha_{n}\right)\left(T_{[n]}^{s} x_{n}-p\right)\right\|^{2} \\
= & \alpha_{n}\left\|x_{n}-p\right\|^{2}+\left(1-\alpha_{n}\right)\left\|T_{[n]}^{s} x_{n}-p\right\|^{2} \\
& -\alpha_{n}\left(1-\alpha_{n}\right)\left\|x_{n}-T_{[n]}^{s} x_{n}\right\|^{2} \\
\leq & \alpha_{n}\left\|x_{n}-p\right\|^{2}+\left(1-\alpha_{n}\right)\left[\left(1+r_{n}\right)^{2}\left\|x_{n}-p\right\|^{2}\right. \\
& \left.+k\left\|x_{n}-T_{[n]}^{s} x_{n}\right\|^{2}\right]-\alpha_{n}\left(1-\alpha_{n}\right)\left\|x_{n}-T_{[n]}^{s} x_{n}\right\|^{2}
\end{aligned}
$$




$$
\begin{aligned}
\leq & {\left[\alpha_{n}\left(1+r_{n}\right)^{2}+\left(1-\alpha_{n}\right)\left(1+r_{n}\right)^{2}\right]\left\|x_{n}-p\right\|^{2} } \\
& -\left(\alpha_{n}-k\right)\left(1-\alpha_{n}\right)\left\|x_{n}-T_{[n]}^{s} x_{n}\right\|^{2} \\
= & \left(1+r_{n}\right)^{2}\left\|x_{n}-p\right\|^{2}-\left(\alpha_{n}-k\right)\left(1-\alpha_{n}\right)\left\|x_{n}-T_{[n]}^{s} x_{n}\right\|^{2} \\
= & \left(1+d_{n}\right)\left\|x_{n}-p\right\|^{2}-\left(\alpha_{n}-k\right)\left(1-\alpha_{n}\right)\left\|x_{n}-T_{[n]}^{s} x_{n}\right\|^{2}
\end{aligned}
$$

where $d_{n}=r_{n}^{2}+2 r_{n}$. Since $k+\epsilon<\alpha_{n}<1-\epsilon$ for all $n$, from (24) we have

$$
\left\|x_{n+1}-p\right\|^{2} \leq\left(1+d_{n}\right)\left\|x_{n}-p\right\|^{2}-\epsilon^{2}\left\|x_{n}-T_{[n]}^{s} x_{n}\right\|^{2} .
$$

Now (26) implies that

$$
\left\|x_{n+1}-p\right\|^{2} \leq\left(1+d_{n}\right)\left\|x_{n}-p\right\|^{2} .
$$

Since $\sum_{n=1}^{\infty} r_{n}<\infty$ thus $\sum_{n=1}^{\infty} d_{n}<\infty$, it follows by Lemma 1.2 , we know that $\lim _{n \rightarrow \infty}\left\|x_{n}-p\right\|$ exists and so $\left\{x_{n}\right\}$ is bounded. Consider (26) again yields that

$$
\left\|x_{n}-T_{[n]}^{s} x_{n}\right\|^{2} \leq \frac{1}{\epsilon^{2}}\left[\left\|x_{n}-p\right\|^{2}-\left\|x_{n+1}-p\right\|^{2}\right]+\frac{d_{n}}{\epsilon^{2}}\left\|x_{n}-p\right\|^{2} .
$$

Since $\left\{x_{n}\right\}$ is bounded and $d_{n} \rightarrow 0$ as $n \rightarrow \infty$. So, we get

$$
\left\|x_{n}-T_{[n]}^{s} x_{n}\right\| \rightarrow 0 \text { as } n \rightarrow \infty .
$$

From the definition of $\left\{x_{n}\right\}$, we have

$$
\left\|x_{n+1}-x_{n}\right\|=\left(1-\alpha_{n}\right)\left\|x_{n}-T_{[n]}^{s} x_{n}\right\| \rightarrow 0, \text { as } n \rightarrow \infty .
$$

So, $\left\|x_{n}-x_{n+l}\right\| \rightarrow 0$ as $n \rightarrow \infty$ and for all $l<N$. Now for $n \geq N$, and since $T$ is uniformly Lipschitzian (by Remark 1.1) with Lipschitz constant $L>0$, so we have

$$
\begin{aligned}
\left\|x_{n}-T_{[n]} x_{n}\right\| \leq & \left\|x_{n}-T_{[n]}^{s} x_{n}\right\|+\left\|T_{[n]}^{s} x_{n}-T_{[n]} x_{n}\right\| \\
\leq & \left\|x_{n}-T_{[n]}^{s} x_{n}\right\|+L\left\|T_{[n]}^{s-1} x_{n}-x_{n}\right\| \\
\leq & \left\|x_{n}-T_{[n]}^{s} x_{n}\right\|+L\left[\left\|T_{[n]}^{s-1} x_{n}-T_{[n-N]}^{s-1} x_{n-N}\right\|\right. \\
& \left.\quad+\left\|T_{[n-N]}^{s-1} x_{n-N}-x_{n-N}\right\|+\left\|x_{n-N}-x_{n}\right\|\right] .
\end{aligned}
$$

Since for each $n \geq N, n \equiv(n-N)(\bmod N)$. Thus $T_{[n]}=T_{[n-N]}$, therefore from (31), we have

$$
\begin{aligned}
\left\|x_{n}-T_{[n]} x_{n}\right\| \leq & \left\|x_{n}-T_{[n]}^{s} x_{n}\right\|+L^{2}\left\|x_{n}-x_{n-N}\right\| \\
& +L\left\|T_{[n-N]}^{s-1} x_{n-N}-x_{n-N}\right\|+L\left\|x_{n-N}-x_{n}\right\| .
\end{aligned}
$$


From (29) and (32), we obtain

$$
\left\|x_{n}-T_{[n]} x_{n}\right\| \rightarrow 0 \text { as } n \rightarrow \infty .
$$

Consequently, for any $l \in I=\{0,1, \ldots, N-1\}$,

$$
\begin{aligned}
\left\|x_{n}-T_{[n+l]} x_{n}\right\| \leq & \left\|x_{n}-x_{n+l}\right\|+\left\|x_{n+l}-T_{[n+l]} x_{n+l}\right\| \\
& +\left\|T_{[n+l]} x_{n+l}-T_{[n+l]} x_{n}\right\| \\
\leq & (1+L)\left\|x_{n}-x_{n+l}\right\|+\left\|x_{n+l}-T_{[n+l]} x_{n+l}\right\| \\
& \rightarrow 0 \text { as } n \rightarrow \infty .
\end{aligned}
$$

This implies that

$$
\lim _{n \rightarrow \infty}\left\|x_{n}-T_{[l]} x_{n}\right\|=0, \quad \forall l \in I=\{0,1, \ldots, N-1\} .
$$

This completes the proof.

Theorem 2.2. Let $C$ be a closed convex compact subset of a Hilbert space $H$. Let $N \geq 1$ be an integer. Let for each $0 \leq i \leq N-1, T_{i}: C \rightarrow C$ be $N k_{i}$-strictly asymptotically pseudo-contraction mappings for some $0 \leq k_{i}<1$ and $\sum_{n=1}^{\infty} r_{n}<$ $\infty$. Let $k=\max \left\{k_{i}: 0 \leq i \leq N-1\right\}$ and $r_{n}=\max \left\{r_{n_{i}}: 0 \leq i \leq N-1\right\}$. Assume that $F=\bigcap_{i=0}^{N-1} F\left(T_{i}\right) \neq \emptyset$. Given $x_{0} \in C$, let $\left\{x_{n}\right\}_{n=0}^{\infty}$ be the sequence generated by an implicit iteration scheme (14). Assume that the control sequence $\left\{\alpha_{n}\right\}$ is chosen so that $k+\epsilon<\alpha_{n}<1-\epsilon$ for all $n$ and for some $\epsilon \in(0,1)$. Then $\left\{x_{n}\right\}$ converges strongly to a common fixed point of the family $\left\{T_{i}\right\}_{i=0}^{N-1}$.

Proof. We only conclude the difference. By compactness of $C$ this immediately implies that there is a subsequence $\left\{x_{n_{j}}\right\}$ of $\left\{x_{n}\right\}$ which converges to a common fixed point of $\left\{T_{i}\right\}_{i=0}^{N-1}$, say, $p$. Combining (27) with Lemma 1.6, we have $\lim _{n \rightarrow \infty}\left\|x_{n}-p\right\|=0$. This completes the proof.

Remark 2.3. Theorem 2.2 extends and improves the corresponding result of Liu [9] in the following ways:

(i) We removed the uniformly L-Lipschitzian condition.

(ii) The modified Mann iteration process is replaced by implicit iteration process for a finite family of mappings.

For our next result, we shall need the following definition:

Definition 2.4. A mapping $T: C \rightarrow C$ is said to be semi-compact, if for any bounded sequence $\left\{x_{n}\right\}$ in $C$ such that $\lim _{n \rightarrow \infty}\left\|x_{n}-T x_{n}\right\|=0$ there exists a subsequence $\left\{x_{n_{i}}\right\} \subset\left\{x_{n}\right\}$ such that $\lim _{i \rightarrow \infty} x_{n_{i}}=x \in C$.

Theorem 2.5. Let $C$ be a closed convex subset of a Hilbert space $H$. Let $N \geq 1$ be an integer. Let for each $0 \leq i \leq N-1, T_{i}: C \rightarrow C$ be $N k_{i}$-strictly asymptotically pseudo-contraction mappings for some $0 \leq k_{i}<1$ and $\sum_{n=1}^{\infty} r_{n}<\infty$. Let $k=$ $\max \left\{k_{i}: 0 \leq i \leq N-1\right\}$ and $r_{n}=\max \left\{r_{n_{i}}: 0 \leq i \leq N-1\right\}$. Assume that $F=\bigcap_{i=0}^{N-1} F\left(T_{i}\right) \neq \emptyset$. Given $x_{0} \in C$, let $\left\{x_{n}\right\}_{n=0}^{\infty}$ be the sequence generated by an implicit iteration scheme (14). Assume that the control sequence $\left\{\alpha_{n}\right\}$ is chosen 
so that $k+\epsilon<\alpha_{n}<1-\epsilon$ for all $n$ and for some $\epsilon \in(0,1)$. Assume that one member of the family $\left\{T_{i}\right\}_{i=0}^{N-1}$ be semi-compact. Then $\left\{x_{n}\right\}$ converges strongly to a common fixed point of the family $\left\{T_{i}\right\}_{i=0}^{N-1}$.

Proof. Without loss of generality, we can assume that $T_{1}$ is semi-compact. It follows from (35) that

$$
\lim _{n \rightarrow \infty}\left\|x_{n}-T_{[1]} x_{n}\right\|=0 .
$$

By the semi-compactness of $T_{1}$, there exists a subsequence $\left\{x_{n_{k}}\right\}$ of $\left\{x_{n}\right\}$ such that $x_{n_{k}} \rightarrow u \in C$ strongly. Since $C$ is closed, $u \in C$, and furthermore,

$$
\lim _{n_{k} \rightarrow \infty}\left\|x_{n_{k}}-T_{[l]} x_{n_{k}}\right\|=\left\|u-T_{[l]} u\right\|=0,
$$

for all $l \in I=\{0,1, \ldots, N-1\}$. Thus $u \in F$. Since $\left\{x_{n_{k}}\right\}$ converges strongly to $u$ and $\lim _{n \rightarrow \infty}\left\|x_{n}-u\right\|$ exists, it follows from Lemma 1.2 that $\left\{x_{n}\right\}$ converges strongly to $u$. This completes the proof.

Remark 2.6. Theorem 2.5 extends and improves the corresponding result of Kim and $X u[8]$.

Remark 2.7. Theorem 2.5 also extends and improves Theorem 1.6 of Osilike and Akuchu [15] from asymptotically pseudocontractive mappings to strictly asymptotically pseudocontractive mappings.

We now prove strong convergence of $k$-strictly asymptotically pseudo-contractive mappings $\left\{T_{i}\right\}_{i=0}^{N-1}$ using algorithm (18):

Theorem 2.8. Let $C$ be a closed convex subset of a Hilbert space $H$. Let $N \geq 1$ be an integer. Let for each $0 \leq i \leq N-1, T_{i}: C \rightarrow C$ be $N k_{i}$-strictly asymptotically pseudo-contraction mappings for some $0 \leq k_{i}<1, \sum_{n=1}^{\infty} r_{n}<\infty$ and $I-T_{[n]}$ is demiclosed at zero. Let $k=\max \left\{k_{i}: 0 \leq i \leq N-1\right\}$ and $r_{n}=\max \left\{r_{n_{i}}: 0 \leq\right.$ $i \leq N-1\}$. Assume that $F=\bigcap_{i=0}^{N-1} F\left(T_{i}\right) \neq \emptyset$. Let $\left\{x_{n}\right\}_{n=0}^{\infty}$ be the sequence generated by an the algorithm (18). Assume that the sequence $\left\{\alpha_{n}\right\}$ is chosen so that $\sup _{n \geq 0} \alpha_{n}<1$. Then $\left\{x_{n}\right\}$ converges strongly to $P_{F}\left(x_{0}\right)$.

Proof. By Lemma 1.3, we observe that $C_{n}$ is convex.

Now, for all $p \in F$, using Lemma 1.2(ii), we have

$$
\begin{aligned}
\left\|y_{n}-p\right\|^{2}= & \left\|\alpha_{n} x_{n}+\left(1-\alpha_{n}\right) T_{[n]}^{s} x_{n}-p\right\|^{2} \\
= & \left\|\alpha_{n}\left(x_{n}-p\right)+\left(1-\alpha_{n}\right)\left(T_{[n]}^{s} x_{n}-p\right)\right\|^{2} \\
= & \alpha_{n}\left\|x_{n}-p\right\|^{2}+\left(1-\alpha_{n}\right)\left\|T_{[n]}^{s} x_{n}-p\right\|^{2} \\
& -\alpha_{n}\left(1-\alpha_{n}\right)\left\|x_{n}-T_{[n]}^{s} x_{n}\right\|^{2}
\end{aligned}
$$




$$
\begin{aligned}
\leq & \alpha_{n}\left\|x_{n}-p\right\|^{2}+\left(1-\alpha_{n}\right)\left[\left(1+r_{n}\right)^{2}\left\|x_{n}-p\right\|^{2}\right. \\
& \left.+k\left\|x_{n}-T_{[n]}^{s} x_{n}\right\|^{2}\right]-\alpha_{n}\left(1-\alpha_{n}\right)\left\|x_{n}-T_{[n]}^{s} x_{n}\right\|^{2} \\
\leq & {\left[\alpha_{n}\left(1+r_{n}\right)^{2}+\left(1-\alpha_{n}\right)\left(1+r_{n}\right)^{2}\right]\left\|x_{n}-p\right\|^{2} } \\
& -\left(\alpha_{n}-k\right)\left(1-\alpha_{n}\right)\left\|x_{n}-T_{[n]}^{s} x_{n}\right\|^{2} \\
= & \left(1+r_{n}\right)^{2}\left\|x_{n}-p\right\|^{2}-\left(\alpha_{n}-k\right)\left(1-\alpha_{n}\right)\left\|x_{n}-T_{[n]}^{s} x_{n}\right\|^{2} \\
\leq & \left(1+r_{n}\right)^{2}\left\|x_{n}-p\right\|^{2}+\left(k-\alpha_{n}\right)\left(1-\alpha_{n}\right)\left\|x_{n}-T_{[n]}^{s} x_{n}\right\|^{2} \\
\leq & \left\|x_{n}-p\right\|^{2}+\left(k-\alpha_{n}\right)\left\|x_{n}-T_{[n]}^{s} x_{n}\right\|^{2}+\lambda_{n},
\end{aligned}
$$

so $p \in C_{n}$ for all $n$. Thus $F \subset C_{n}$ for all $n$.

Next we show that $F \subset Q_{n}$ for all $n \geq 0$, for this we use induction.

For $n=0$, we have $F \subset C=Q_{0}$. Assume that $F \subset Q_{n}$.

Since $x_{n+1}$ is the projection of $x_{0}$ onto $C_{n} \cap Q_{n}$, by Lemma 1.4, we have

$$
\left\langle x_{n+1}-z, x_{0}-x_{n+1}\right\rangle \geq 0 \quad \forall z \in C_{n} \cap Q_{n} .
$$

As $F \subset C_{n} \cap Q_{n}$ by the induction assumption, the last inequality holds, in particular, for all $z \in F$. This together with the definition of $Q_{n+1}$ implies that $F \subset Q_{n+1}$. Hence $F \subset Q_{n}$ for all $n \geq 0$.

Now, since $x_{n}=P_{Q_{n}}\left(x_{0}\right)$ (by the definition of $Q_{n}$ ), and since $F \subset Q_{n}$, we have

$$
\left\|x_{n}-x_{0}\right\| \leq\left\|p-x_{0}\right\| \quad \forall p \in F .
$$

In particular, $\left\{x_{n}\right\}$ is bounded and

$$
\left\|x_{n}-x_{0}\right\| \leq\left\|q-x_{0}\right\| \text {, where } q=P_{F}\left(x_{0}\right) .
$$

The fact $x_{n+1} \in Q_{n}$ asserts that $\left\langle x_{n+1}-x_{n}, x_{n}-x_{0}\right\rangle \geq 0$. This together with Lemma 1.2(i), implies that

$$
\begin{aligned}
\left\|x_{n+1}-x_{n}\right\|^{2} & =\left\|\left(x_{n+1}-x_{0}\right)-\left(x_{n}-x_{0}\right)\right\|^{2} \\
& =\left\|x_{n+1}-x_{0}\right\|^{2}-\left\|x_{n}-x_{0}\right\|^{2}-2\left\langle x_{n+1}-x_{n}, x_{n}-x_{0}\right\rangle \\
& \leq\left\|x_{n+1}-x_{0}\right\|^{2}-\left\|x_{n}-x_{0}\right\|^{2} .
\end{aligned}
$$

It follows that,

$$
\left\|x_{n+1}-x_{n}\right\| \rightarrow 0 .
$$

By the fact $x_{n+1} \in C_{n}$ we get

$$
\begin{aligned}
\left\|x_{n+1}-y_{n}\right\|^{2} \leq & \left\|x_{n+1}-x_{n}\right\|^{2} \\
& +\left(k-\alpha_{n}\right)\left\|x_{n}-T_{[n]}^{s} x_{n}\right\|^{2}+\lambda_{n} .
\end{aligned}
$$


Moreover, since $y_{n}=\alpha_{n} x_{n}+\left(1-\alpha_{n}\right) T_{[n]}^{s} x_{n}$, we deduce that

$$
\begin{aligned}
\left\|x_{n+1}-y_{n}\right\|^{2}= & \alpha_{n}\left\|x_{n+1}-x_{n}\right\|^{2} \\
& +\left(1-\alpha_{n}\right)\left\|x_{n+1}-T_{[n]}^{s} x_{n}\right\|^{2} \\
& -\alpha_{n}\left(1-\alpha_{n}\right)\left\|x_{n}-T_{[n]}^{s} x_{n}\right\|^{2} .
\end{aligned}
$$

Substituting (43) into (42) to get

$$
\begin{aligned}
\left(1-\alpha_{n}\right)\left\|x_{n+1}-T_{[n]}^{s} x_{n}\right\|^{2} \leq & \left(1-\alpha_{n}\right)\left\|x_{n+1}-x_{n}\right\|^{2} \\
& +k\left\|x_{n}-T_{[n]}^{s} x_{n}\right\|^{2}+\lambda_{n} .
\end{aligned}
$$

Since $\alpha_{n}<1$ for all $n$, the last inequality becomes,

$$
\begin{aligned}
\left\|x_{n+1}-T_{[n]}^{s} x_{n}\right\|^{2} \leq & \left\|x_{n+1}-x_{n}\right\|^{2}+k\left\|x_{n}-T_{[n]}^{s} x_{n}\right\|^{2} \\
& +\frac{\lambda_{n}}{\rho},
\end{aligned}
$$

for some positive number $\rho>0$, such that $\alpha_{n}<\rho<1$.

But on the other hand, we compute

$$
\begin{aligned}
\left\|x_{n+1}-T_{[n]}^{s} x_{n}\right\|^{2}= & \left\|x_{n+1}-x_{n}\right\|^{2}+2\left\langle x_{n+1}-x_{n}, x_{n}-T_{[n]}^{s} x_{n}\right\rangle \\
& +\left\|x_{n}-T_{[n]}^{s} x_{n}\right\|^{2} .
\end{aligned}
$$

By (44) and (45), we get

$$
(1-k)\left\|x_{n}-T_{[n]}^{s} x_{n}\right\|^{2} \leq \frac{\lambda_{n}}{\rho}-2\left\langle x_{n+1}-x_{n}, x_{n}-T_{[n]}^{s} x_{n}\right\rangle .
$$

Therefore

$$
\begin{aligned}
\left\|x_{n}-T_{[n]}^{s} x_{n}\right\|^{2} \leq & \frac{\lambda_{n}}{\rho(1-k)}-\frac{2}{1-k}\left\langle x_{n+1}-x_{n}, x_{n}-T_{[n]}^{s} x_{n}\right\rangle \\
& \rightarrow 0 \text { as } n \rightarrow \infty .
\end{aligned}
$$

Now,

$$
\begin{aligned}
\left\|x_{n}-T_{[n]} x_{n}\right\| \leq & \left\|x_{n}-T_{[n]}^{s} x_{n}\right\|+\left\|T_{[n]}^{s} x_{n}-T_{[n]} x_{n}\right\| \\
\leq & \left\|x_{n}-T_{[n]}^{s} x_{n}\right\|+\left(1+r_{1}\right)\left\|T_{[n]}^{s-1} x_{n}-x_{n}\right\| \\
& \rightarrow 0 \text { as } n \rightarrow \infty .
\end{aligned}
$$

Now, since $I-T_{[n]}$ is demiclosed at zero, (48) imply that $x_{n} \rightarrow x$, where $x$ is a weak limit of $\left\{x_{n}\right\}$ and hence $\omega_{w}\left(x_{n}\right) \subset F\left(T_{i}\right)$ for any $i=0,1, \ldots, N-1$. So, $\omega_{w}\left(x_{n}\right) \subset F=\bigcap_{i=0}^{N-1}$. This fact, the inequality (40) and Lemma 1.5 implies that $\left\{x_{n}\right\} \rightarrow q=P_{F}\left(x_{0}\right)$, that is, $\left\{x_{n}\right\}$ converges strongly to $P_{F}\left(x_{0}\right)$. This completes the proof. 
Remark 2.9. Theorem 2.8 extends Theorem 3.1 of Thakur [19] to the case of finite family of mappings and implicit iteration process considered in this paper.

Acknowledgement. Our sincere thanks to the referee for his valuable suggestions and comments on the manuscript and also thanks to Prof. A. Banerjee for providing a manuscript of Osilike [14].

\section{References}

[1] Acedo, G. L. and Xu, H. K., "Iterative methods for strict pseudo-contractions in Hilbert spaces", Nonlinear Anal. 67 (2007), 2258 - 2271.

[2] Browder, F. E. and Petryshyn, W. V., "Construction of fixed points of nonlinear mappings in Hilbert spaces", J. Math. Anal. Appl. 20 (1967), 197 - 228.

[3] Genel, A. and Lindenstrauss, J., "An example concerning fixed points", Israel J. Math. 22(1) (1975), $81-86$

[4] Goebel, K. and Kirk, W. A., "A fixed point theorem for asymptotically nonexpansive mappings", Proc. Amer. Math. Soc. 35 (1972), 171 - 174.

[5] Hicks, T. L. and Kubicek, J. R., "On the Mann iterative process in Hilbert space", J. Math. Anal. Appl. 59 (1977), 498 - 504.

[6] Ishikawa, S., "Fixed points by a new iteration method", Proc. Amer. Math. Soc. 44 (1974), $147-150$.

[7] Kim, T. H. and Xu, H. K., "Strong convergence of modified Mann iterations for asymptotically nonexpansive mappings and semigroups", Nonlinear Anal. 64 (2006), 1140 - 1152.

[8] Kim, T. H. and Xu, H. K., "Convergence of the modified Mann's iteration method for asymptotically strictly pseudocontractive mapping", Nonlinear Anal. (2007), doi:10.1016/j.na.2007.02.029.

[9] Liu, Q., "Convergence theorems of the sequence of iterates for asymptotically demicontractive and hemicontractive mappings", Nonlinear Anal. 26 (1996), 1835 - 1842.

[10] Martinez-Yanex, C. and Xu, H. K., "Strong convergence of the $C Q$ method for fixed point processes", Nonlinear Anal. 64 (2006), 2400 - 2411.

[11] Marino, G. and $\mathrm{Xu}, \mathrm{H}$. K., "Weak and strong convergence theorems for strict pseudocontractions in Hilbert spaces", J. Math. Anal. Appl. 329 (2007), 336 - 346.

[12] Mann, W. R., "Mean value methods in iteration", Proc. Amer. Math. Soc. 4 (1953), 506 510 .

[13] Nakajo, K. and Takahashi, W., "Strong convergence theorems for nonexpansive mappings and nonexpansive semigroups", J. Math. Anal. Appl. 279 (2003), 372 - 379.

[14] Osilike, M. O., "Iterative approximation of fixed points of asymptotically demicontractive mappings", Indian J. pure appl. Math. 29(12) (1998), 1291 - 1300.

[15] Osilike, M. O. and Akuchu, B. G., "Common fixed points of a finite family of asymptotically pseudocontractive maps", Fixed Point Theory and Appl. 2(2004), 81 - 88.

[16] Osilike, M. O. and Udomene, A., "Demiclosedness principle and convergence results for strictly pseudocontractive mappings of Browder-Petryshyn type", J. Math. Anal. Appl. 256 (2001), 431 - 445.

[17] Osilike, M. O., Aniagbosor, S. C. and Akuchu, B. G., "Fixed points of asymptotically demicontractive mappings in arbitrary Banach spaces", PanAm. Math. J. 12 (2002), 77 - 78.

[18] Reich, S., "Weak convergence theorems for nonexpansive mappings in Banach spaces", J. Math. Anal. Appl. 67 (1979), $274-276$.

[19] Thakur, B. S., "Convergence of strictly asymptotically pseudo-contractions", Thai J. Math. 5(1) (2007), $41-52$.

[20] Xu, H. K. and Ori, R. G., "An implicit iteration process for nonexpansive mappings", Numer. Funct. Anal. Optim. 22 (2001), $767-773$. 